trol the inspiratory effort; and $I$ have never known it fail to give temporary relief : in some instances it has saved life. I am aware it may be said such compression of the chest is likely to prove injurious to the infant's growth ; and, certainly, it should be discontinued as soon as the cause for its application disappears; but where the attacks of dyspnoea are threatening daily and hourly to cut off the patient, immediate benefit mast be sought at the risk of remote ill consequences.

The other points in the treatment may be summarily recounted-change of air, warm clothing, nutritious diet, great attention to the state of the digestive organs, guarding especially against constipation, are the chief; and to these may be added, local applications, counter-irritants, iodine ointment, \&c. to the base of the neck, though the curative effects of such will prove inconsiderable. In the instances of laryngismus stridulus, complicated with cerebral dis. order, the treatment must so entirely be regulated by the circumstances of each individual case, that it is impossible in a paper like the present to give it even in outline; but one precaution the writer will venture to suggest to those who have such cases under treatment, avoid the "nimia medici diligentia." Where symptoms of congestion or inflammation are present, cautious depletion and the use of mercury may prove useful; but the cerebral irritation may be most intense, the carpo-pedal contractions at times present, the laryngismus stridulus most distinct, and yet the case be benefitted by a soothing or even strengthening treatment; and the symptoms, on the other hand, be exasperated to a tenfold degree, by antiphlogistic measures.

\section{THYMIC ASTHMA.}

\section{To the Editor of The LanceT.}

Sir :-In answer to your appeal to medical men respectiug the disease called by the Germans thymic asthma, I beg to say that I have treated successfully $t$ wo cases of it. The whole of the children in Mr. Underwood's family, in which these cases oc. curred, have soon after birth manifested the asthmic constitution; have become ill from time to time from slight causes; two of them have had distortions of the spine and extre. mities, and hve out of nine have died of dis. eases incident to such a state of body; such as subacute disease of the brain, lungs, intestinal canal, \&c., in which it was found impossible to have recourse to active depletory remedies without doing injury. The cases of thymic asthma were characterised by spasmodic attacks of the muscles of the upper part of the thorax, neck, and face, occasioning severe stricture of these parts, and occurring frequently at night-induced at all times by anything that disturbed the tranquillity of the little patient's mind, and particularly during a fit of crying. During these paroxysms the muscles became stiffened, the features violently distorted, the face black, respiration suspended, and the patient very much exhausted. When the spasms gave way there was a peculiar croaking sound of the voice, which was not present after the fit had subsided, and very different to the sound produced by croup : in the intervals, the patient became lively, could eat and drink without much difficulty, and was free from acute disease of the lungs and bronchial tubes; having at most a slight cough, without much dyspnoea, and only mild febrile symptoms. During the paroxysms, change of position always gave relief. The mode of treatment adopted in these cases was as follows:-One.eighth of a grain of tartarised antimony with half a grain of submuriate of mercury, was taken every four hours, afterwards every six and eight hours, then twice a-day; in the intervals, a saline mixture with hyoseyamus or poppy was given; and lastly, small doses of mercury with chalk once or twice a-day, and a mixture with sulphuric acid and syrup; to which may be added, a mild nourishing diet.

The elder of these patients has up to the present time (now more than two years since the attack) a peculiar sound of the voice whenever she cries or is pettish; the other patient is alive. I am, Sir, yours respectfully,

St. James's, Barton, Bristol,

James Prowse. May 14, 1841 .

\section{ON THE}

\section{APPLICATION OF LEECHES TU} THE PROSTATE GLAND.

\author{
By William Craig, Esq., Surgeon, Ayr.
}

\section{To the Editor of The Lancet.}

SIR :-I am glad to have it in my power to corroborate the statement made by $\mathrm{Dr}$. Henderson, of Perth, in The Lancet for January 30th, of the good effects of leeches applied to the prostate gland through the rectum. I may state, however, that this kind of treatment is not perfectly new; and Dr. Henderson is not the first who recom. menis it, although from his method of applying leeches in this situation, it is evident that he deserves the credit of originality, in so far as he seems to have had no assistance from the mode described by M. Begin, who gives, in the "Dictionnaire de Medecine et Chirurgie Pratique," an account of a method of applying leeches to the prostate through the rectum. I applied leeches in 